\title{
Application of Magnetic Resonance Techniques to evaluate soil compaction after grazing
}

\author{
B. Carrero-González*, M.T. De La Cruz, M.A. Casermeiro \\ Dpto. de Edafología, Facultad de Farmacia, Universidad Complutense de Madrid. Plaza Ramón y Cajal, s/n. \\ 28040 Madrid, Spain.*Corresponding author: bcarrero@farm.ucm.es
}

\begin{abstract}
Grazing constitutes one of the most important processes of soil degradation due to compaction, and it affects both vegetation and soil in arid and semiarid ecosystems. Compaction modifies the soil structure and causes an increase in the proportion of small aggregates, which consequently leads to an increase in bulk soil density. Compaction also produces a decrease in soil organic carbon content. The soil becomes more densely packed, causing reductions in porosity and storage capacity.

Magnetic Resonance Imaging (MRI) was used to obtain a relative estimate of soil water content and porosity. The signal intensity from proton density images, which corresponds to the amount of water present in a sample, is lower in compacted soil. As calculated from the image signal intensity, the porosity percentage is also lower in grazing soils in comparison with natural recovery soils.

H NMR relaxometry studies demonstrate shorter T2 and T1 relaxation times in grazing soil samples, suggesting lower pore sizes in these soils. Moreover, the grazing samples have a monomodal distribution of $\mathrm{T} 1$ with a narrow band, indicating greater homogeneity in the pore sizes. The bimodal distribution of T2 complements this result and indicates a greater proportion of smaller-size pores with greater homogeneity between them.

There is a significant positive correlation between the porosity values determined by both methods, which demonstrates the validity of the MR technique. The relaxation times also show positive and significant correlations with analytical porosity.

The application of MR techniques to soil compaction studies demonstrated the natural recovery of the physical properties of deteriorated soil after grazing damage in pastoral systems brought about by complete animal exclusion for ten years.
\end{abstract}

Keywords: Soil compaction, porosity, Magnetic Resonance Imaging, Relaxometry, grazing. 


\section{Introduction}

Grazing constitutes one of the most significant processes of soil degradation due to compaction. The constant trampling of the soil by animals leads to its compaction, reducing the volume of the spaces in and increasing the bulk density of the soils. The particles are more densely packed, which leads to a decrease in porosity, particularly regarding macropores (Glinski and Lipiec, 1990), and alters the soil surface. Soil compaction is directly associated with a decrease in organic matter in the surface horizon (Xie and Witting, 2004). This observation can be attributed both to the poor living conditions many soil organisms encounter in these compacted environments and to the nature of the soil's plant cover (grasslands). The consequences of these processes include the reduction in of the infiltration and water storage capacities of soils (Li et al., 2008), a decrease in grassland productivity grazing quality (Martinez and Zinck, 2004), and the general acceleration of soil erosion.

A soil's vulnerability to degradation depends largely on its properties, particularly those properties related to permeability and porosity: texture, structure, coloid content (organic matter, clay), etc. Soils with fine textures and high percentages of silt and clay retain greater quantities of water than soils with a coarse texture; these fine-textured soils are more compact, and the movement of air and water through them is slower (Daum, 1996). Soil structure also affects the movement and retention of water. Loss of structure is therefore a form of soil degradation; compaction reduces the pore space and blocks the flow of water (Bronick and Lal, 2005). Organic matter constitutes an essential component in the formation of structure, although its content in the soil is lower than that of other mineral components. Soils with high organic matter produce more stable aggregates that resist compaction, while soils with low proportions of organic matter are more susceptible to compaction (Schulten and Leinweber, 2000).

The scarcity of biomass in a grazed area leaves the soil surface unprotected, which leads to its disintegration from the direct impact of rain and a decrease in infiltration (Casermeiro et al., 2004). These factors cause slower drainage rates in grassland soils.

Magnetic Resonance Imaging (MRI) can be used to obtain a relative estimate of a soil's water content and can provide absolute values by comparison of the signal intensity obtained with that of a known quantity of water (Hall et al., 1997). Any Magnetic Resonance (MR) image of soil depends on the MR signal elicited from the nuclei of hydrogen atoms in the water contained by the soil. This signal is defined by its amplitude, frequency, phase and duration, and it is affected by certain MR properties of water in soil, such as $\mathrm{T} 1$ and $\mathrm{T} 2$ relaxation time constants.

In MR experiments, the soil sample is exposed to a magnetic field that induces a nuclear magnetisation of water protons along the direction of the magnetic field. A sequence of radio frequency (RF) pulses reorients the magnetisation so that it is no longer in its equilibrium state. The relaxation, or the return to equilibrium position, can be quantitatively measured. The signal acquired during relaxation process contains information both on the density of nuclei ${ }^{1} \mathrm{H}$, from which can be obtained the porosity, and on the properties of the pore space, which can be extracted from the $\mathrm{T} 1$ and $\mathrm{T} 2$ relaxation time constants (Bortolotti et al., 2006b).

An assessment of MRI as a porosity measurement tool for porous media other than soils, such as rock samples, was conducted by Borgia et al (1996).

The main limitations encountered during the study of the soil-water system with MRI are poor signal-tonoise ratio $(\mathrm{S} / \mathrm{N})$, poor spatial resolution and image 
distortions, all of which are primarily caused by the variation of the magnetic susceptibility in the soil. The contents of clay, free iron oxide, exchangeable cations and organic matter influence the MR parameters and therefore the ability of MRI to accurately detect soil water (Hall et al., 1997). These difficulties can be overcome by using the appropriate MRI pulse sequences.

The MR signals also supply information on the properties of the pore space, which can be deduced by relaxometry (Schaumann et al., 2005). ${ }^{1} \mathrm{H}$ NMR relaxometry was first used in soil science in 1970 to measure the water content of soil samples (Prebble and Currie, 1970). The correspondence between pore size distribution and relaxation time was established by Brownstein and Tarr (1979), and the dependence of $\mathrm{T} 1$ and $\mathrm{T} 2$ relaxation times on soil type, soil water content and pore size was demonstrated by Van As and Van Dusschoten (1997).

Magnetic Resonance has many advantages over other measurement methods in soil applications. The technique is fast and non-destructive, can determine the total amount of protons in the water contained within the pores and is broadly independent of the solid soil characteristics. The combination of MRI and MR Relaxometry (MRR) methods has already been applied to the study of water absorption kinetics in pore systems (Bortolotti et al., 2006) and yielded a synergetic improvement of the results. However, we found no previous records in the literature of the joint application of both techniques to study soil structure recovery.

The aim of this work was to evaluate both MRI and MRR for the assessment of soil compaction due to grazing and to demonstrate the complementary nature of these two techniques in the study of soil porosity. A case study of the natural regeneration of soil physical properties after grazing was examined. Soil porosity and soil water content were estimated using MR in both grazing soils and no-grazing systems.
To assess the value of MR techniques in this study, the MRI and MRR results for the soils were compared with moisture, bulk density, percentage of water retention, particle density and total porosity data obtained using alternative analytical methodologies.

\section{Material and methods}

\subsection{Characteristics of the study area}

The studies were conducted in the district of Arevalillo de Cega, in the east of the province of Segovia, in the central area of the Iberian Peninsula $\left(40^{\circ} 46^{\prime}\right.$ and $41^{\circ} 35^{\prime} \mathrm{N}, 3^{\circ} 13^{\prime}$ and $4^{\circ} 42^{\prime} \mathrm{W}$ ). The altitude of the area is $1,100 \mathrm{~m}$, its annual average rainfall is 478 $\mathrm{mm}$, and its average temperature is $11.9^{\circ} \mathrm{C}$. The natural vegetation consists of perennial grasslands with a predominance of Thymus mastichina. The soils used in the study were calcareous Leptosols developed on Cretaceous limestone. These soils consist of $60.70 \%$, $13.00 \%$ and $26.30 \%$ sand, silt and clay, respectively (González and Candás, 2004). This area has been used as natural pasture for hundreds of years, over which it has been open to the free transit of sheep.

\subsection{Sampling}

A rectangular area of $3200 \mathrm{~m}^{2}$ was cordoned off for ten years and closed to the passage of sheep. It has been estimated that ten years of grazing is sufficient time to produce soil compaction and restriction of the movement of water through a soil profile due to the modification of its physical parameters (Linnartz et al., 1966). Ten years of no grazing were chosen as a treatment to evaluate the natural recovery of physical properties in grazing-damaged soil.

A paired sample design was employed in this study. Three sample points were located in the ungrazed area (natural recovery treatment, $\mathrm{BN}$ ), and three were located outside of the excluding fence 
(grazing treatment, $\mathrm{BG}$ ). The distance between paired samples (BN1 to BG1, BN2 to BG2 and BN3 to BG3) was 30 metres. A composed sample of the soils $(n=3)$ was taken at each selected point, both in the natural recovery state area (BN samples) and the grazing area (BG samples), at two different depths $(0-10 \mathrm{~cm}, 10-20$ $\mathrm{cm})$. The samples were collected following the methodology proposed by the FAO (2007), and colour was determined in situ using Munsell tables (2009).

Unaltered soil samples were taken at all points using methacrylate cores $(5 \mathrm{~cm}$ inner diameter and $5 \mathrm{~cm}$ high) for studying the magnetic resonance and physical properties of the soils (USDA, 1999).

\subsection{Analytical determinations}

The analytical determinations were conducted on the fine earth fraction after air drying and sieving using the following parameters: organic carbon (OC) by wet oxidation, $\mathrm{pH}$ in water suspension $(1: 2,5)$, and electrical conductivity, EC (ISRIC, 2002). The aggregates were gently isolated while moist, and fractions of less than $53 \mu \mathrm{m}$ and 53-2000 $\mu \mathrm{m}$ were isolated. The percentages by weight of each one were then determined (Cambardella and Elliot, 1992).

The following parameters were determined using the unaltered samples collected in Ejelkamp cylinders: moisture $(\%)$, bulk density $\left(\mathrm{g} / \mathrm{cm}^{3}\right)$, water storage capacity, particle density $\left(\mathrm{g} / \mathrm{cm}^{3}\right)$, and total porosity (\%) (Koorevaar, et al. 1983).

\subsection{Magnetic resonance studies}

All Magnetic Resonance Imaging (MRI) and relaxometry (MRR) experiments were performed using a BIOSPEC BMT 47/40 spectrometer (Bruker, Ettlingen, Germany) at 4.7 Teslas (200 MHz resonance frequency for protons). Magnetic field gradients for imaging were generated by a $12 \mathrm{~cm}$ actively shielded gradient set capable of reaching $200 \mathrm{mT} / \mathrm{m}$.

The individual unaltered samples, contained in methacrylate cylinders, were previously wetted, and their moisture contents were maintained at approximately $100 \%$ of their water holding capacity (the soils were saturated and allowed to reach equilibrium). Individual samples were placed in a radio frequency birdcage coil (inner diameter of $7 \mathrm{~cm}$ ) for the MR studies.

For the MRI experiments, a global shimming was performed prior to image acquisition. Axial, coronal and sagittal images were acquired for sample localisation using spin-echo experiments. The acquisition parameters for these images were as follows: repetition time $\mathrm{TR}=200 \mathrm{~ms}$, echo time $\mathrm{TE}=10 \mathrm{~ms}$, field of view FOV $=10 \mathrm{~cm}$, slice thickness SLTH $=5 \mathrm{~mm}$, matrix size $=128 \times 128$ and number of acquisition NEX $=1$.

For T2 relaxation time measurements, 20 echoes of axial slices using a spin-echo sequence were acquired. For these experiments, the TR was $2000 \mathrm{~ms}$, and the echo time TE was fixed at $4.5 \mathrm{~ms}$, resulting in an echo train varying from 4.5 to $90 \mathrm{~ms}$. The FOV was $7 \times 7 \mathrm{~cm}^{2}$, and the matrix size was $128 \times 128$. The signal was averaged 4 times. Ten slices with a thickness of $5 \mathrm{~mm}$ were obtained.

T1 relaxation time measurements were conducted on the same slices using a spin-echo sequence. Separate images were acquired at seven different recovery times. TR varied from 250 to $6000 \mathrm{~ms}$, and the TE was $4.5 \mathrm{~ms}$.

Based on the sequences described above, the values for $\mathrm{T} 1$ and $\mathrm{T} 2$ were calculated for several regions of interest (ROI). The Image Sequence Analysis (ISA) utility of the ParaVision 3.0.1 package (Bruker, Ettlingen, Germany) was used to fit the signal intensities to the exponential function of the spin-echo signal (Young et al., 1982). T1 values were calculated from the series of saturation recovery spin-echo im- 
ages with different repetition times (TR), while T2 values were calculated from the series of spin-echo images with different echo times (TE).

The ROI were selected from the interior of the cylinder (upper left corner image of figures $2 \mathrm{a}$ and $2 \mathrm{~b}$ ); the outer edge of the cylinder was ignored to avoid the contribution of any spaces connected to the surface of the cylinder or any possible effect of the cylinder's drag on the soil structure during sample acquisition (Borgia et al., 1996). Signal Intensity of the signal at equilibrium magnetisation was also obtained, and T1, T2 and signal intensity maps were calculated using the same software (ParaVision 3.0.1, Bruker, Ettlingen, Germany).

To calculate porosity from the images, we followed the methods of studies in which this percentage is determined by relating the measurement of the signal intensity with internal references (Borgia et al., 2001). The final processing of the images was performed using Image $J$ software for Windows.

The relaxometry experiments were conducted on the same samples immediately after the image experiments, without any further handling of the samples. These measurements were used to obtain the distribution curves using the modified UpenWin program (López-Arce et al., 2010). For T1, a standard IR sequence was used, with 50 inversion times varying from 15 to $750 \mathrm{~ms}$. For T2, a CPMG sequence was used, and 50 echoes with TE $=800 \mathrm{~ms}$ were registered.

\subsection{Statistical analysis}

The statistical analysis of the results was performed using the SPSS v.19 statistics program (Microsoft Windows). A one-way analysis of variance (ANOVA) was performed using the Fisher-Snedecor F distribution method with a confidence level of over $95 \%$ ( $p<0.05$ ). Bilateral correlation studies were also conducted, using the Pearson method.

\section{Results and discussion}

Table 1 shows the descriptions of the soils and the results of soil parameter measurements for both the grazing areas (BG treatment) and the ungrazed regions (BN treatment), in which the natural recovery of soil physical properties was evaluated after ten years of no grazing. 
Table 1. Soil characteristics: morphological description and soil parameters (FAO, 2007).

\begin{tabular}{|c|c|c|c|c|c|c|c|c|c|c|c|c|}
\hline $\begin{array}{l}\text { Charac- } \\
\text { teristics }\end{array}$ & \multicolumn{4}{|c|}{ Paired samples 1} & \multicolumn{4}{|c|}{ Paired samples 2} & \multicolumn{4}{|c|}{ Paired samples 3} \\
\hline $\begin{array}{l}\text { Locali- } \\
\text { zation }\end{array}$ & $\begin{array}{r}\text { Ungraze } \\
(\mathrm{Nat} \\
\text { recov }\end{array}$ & $\begin{array}{l}\text { ed area } \\
\text { tural } \\
\text { very) }\end{array}$ & Graze & $\mathrm{d}$ area & $\begin{array}{r}\text { Ungraz } \\
(\mathrm{Na} \\
\text { reco } \\
\end{array}$ & $\begin{array}{l}\text { ed area } \\
\text { tural } \\
\text { very) }\end{array}$ & Graze & $\mathrm{d}$ area & $\begin{array}{r}\text { Ungraze } \\
(\mathrm{Nat} \\
\text { recov } \\
\end{array}$ & $\begin{array}{l}\text { ed area } \\
\text { tural } \\
\text { very) } \\
\end{array}$ & Graze & area \\
\hline \multirow[t]{2}{*}{ ID } & BN & N1 & & $\mathrm{s} 1$ & & $\mathrm{~N} 2$ & $\mathrm{BC}$ & $\mathrm{s} 2$ & BN & N3 & & $\mathrm{G} 3$ \\
\hline & BN1-A & BN1-B & BG1-A & BG1-B & BN2-A & BN2-B & BG2-A & BG2-B & BN3-A & BN3-B & BG3-A & BG3-B \\
\hline Horizon & Ah1 & Ah2 & Ah1 & Ah2 & Ah1 & Ah2 & Ah1 & Ah2 & Ah1 & Ah2 & Ah1 & $\mathrm{Ah} 2$ \\
\hline $\begin{array}{l}\text { Depth } \\
(\mathrm{cm})\end{array}$ & $0-10$ & $10-20$ & $0-10$ & $10-20$ & $0-10$ & $10-20$ & $0-10$ & $10-20$ & $0-10$ & $10-20$ & $0-10$ & $10-20$ \\
\hline $\begin{array}{l}\text { Colour } \\
\text { (moist) }\end{array}$ & $\begin{array}{c}10 \mathrm{YR} \\
4 / 4\end{array}$ & $\begin{array}{c}10 \mathrm{YR} \\
5 / 6\end{array}$ & $\begin{array}{c}10 \mathrm{YR} \\
4 / 6\end{array}$ & $\begin{array}{c}10 \mathrm{YR} \\
5 / 6\end{array}$ & $\begin{array}{c}10 \mathrm{YR} \\
4 / 4\end{array}$ & $\begin{array}{c}10 \mathrm{YR} \\
4 / 6\end{array}$ & $\begin{array}{c}10 \mathrm{YR} \\
4 / 6\end{array}$ & $\begin{array}{c}10 \mathrm{YR} \\
5 / 6\end{array}$ & $\begin{array}{c}10 \mathrm{YR} \\
4 / 4\end{array}$ & $\begin{array}{c}10 \mathrm{YR} \\
5 / 6\end{array}$ & $\begin{array}{c}10 \mathrm{YR} \\
4 / 6\end{array}$ & $\begin{array}{c}10 \mathrm{YR} \\
5 / 6\end{array}$ \\
\hline $\begin{array}{l}\text { Colour } \\
\text { (dry) }\end{array}$ & $\begin{array}{l}10 \mathrm{YR} \\
4 / 6\end{array}$ & $\begin{array}{c}10 \mathrm{YR} \\
5 / 8\end{array}$ & $\begin{array}{c}10 \mathrm{YR} \\
5 / 6\end{array}$ & $\begin{array}{c}10 \mathrm{YR} \\
5 / 8\end{array}$ & $\begin{array}{c}10 \mathrm{YR} \\
4 / 6\end{array}$ & $\begin{array}{l}10 \mathrm{YR} \\
5 / 8\end{array}$ & $\begin{array}{c}10 \mathrm{YR} \\
5 / 6\end{array}$ & $\begin{array}{c}10 \mathrm{YR} \\
5 / 8\end{array}$ & $\begin{array}{c}10 \mathrm{YR} \\
4 / 6\end{array}$ & $\begin{array}{c}10 \mathrm{YR} \\
5 / 8\end{array}$ & $\begin{array}{c}10 \mathrm{YR} \\
5 / 6\end{array}$ & $\begin{array}{c}10 \mathrm{YR} \\
5 / 8\end{array}$ \\
\hline $\begin{array}{l}\text { Struc- } \\
\text { ture }\end{array}$ & $\begin{array}{l}\text { Mo- } \\
\text { derate } \\
\text { granu- } \\
\text { lar me- } \\
\text { dium }\end{array}$ & $\begin{array}{l}\text { Weak } \\
\text { granu- } \\
\text { lar fine }\end{array}$ & $\begin{array}{l}\text { Weak } \\
\text { granu- } \\
\text { lar fine }\end{array}$ & $\begin{array}{l}\text { Weak } \\
\text { granu- } \\
\text { lar fine }\end{array}$ & $\begin{array}{l}\text { Mo- } \\
\text { derate } \\
\text { granu- } \\
\text { lar me- } \\
\text { dium }\end{array}$ & $\begin{array}{l}\text { Weak } \\
\text { granu- } \\
\text { lar fine }\end{array}$ & $\begin{array}{l}\text { Weak } \\
\text { granu- } \\
\text { lar fine }\end{array}$ & $\begin{array}{l}\text { Weak } \\
\text { granu- } \\
\text { lar fine }\end{array}$ & $\begin{array}{l}\text { Mo- } \\
\text { derate } \\
\text { granu- } \\
\text { lar me- } \\
\text { dium }\end{array}$ & $\begin{array}{l}\text { Weak } \\
\text { granu- } \\
\text { lar fine }\end{array}$ & $\begin{array}{l}\text { Weak } \\
\text { granu- } \\
\text { lar fine }\end{array}$ & $\begin{array}{l}\text { Weak } \\
\text { granu- } \\
\text { lar fine }\end{array}$ \\
\hline $\begin{array}{l}\text { Consis- } \\
\text { tency }\end{array}$ & 1.1.2.2 & - & 1.1 .3 .3 & - & 1.1 .2 .2 & - & 1.1.3.3 & - & 1.1.2.2 & - & 1.1 .3 .3 & - \\
\hline $\begin{array}{l}\mathrm{pH} \\
(\mathrm{H} 2 \mathrm{O})\end{array}$ & 7.58 & 7.90 & 7.84 & 8.01 & 7.29 & 7.51 & 7.83 & 8.07 & 6.64 & 7.00 & 7.75 & 7.89 \\
\hline $\begin{array}{l}\mathrm{EC} \\
(\mu \mathrm{S} / \mathrm{cm})\end{array}$ & 70.2 & 76.5 & 64.6 & 72.7 & 56.0 & 39.8 & 46.0 & 44.6 & 44.2 & 33.9 & 43.1 & 88.1 \\
\hline $\begin{array}{l}\text { Organic } \\
\text { Carbon } \\
\%\end{array}$ & 2.21 & 0.85 & 1.03 & 0.86 & 2.18 & 0.98 & 1.49 & 0.77 & 1.88 & 1.01 & 1.45 & 1.12 \\
\hline
\end{tabular}

The changes observed in the ungrazed soils after ten years of sheep exclusion are particularly evident in surface horizons $(0-10 \mathrm{~cm}$ depth), as was reported previously by Drewry et al. (2006) in short-term (one year of no grazing) and long-term (no grazing for up to three years) studies. The grazed areas show a slight increase in the chroma value. There is a clear trend of decreasing organic carbon (OC) in the surface horizons of grazing soil samples. These results agree with those of Sigua et al. (2009) and Bisigato et al. (2008), in which the reduction in soil organic matter was attributed to diminished plant cover due to grazing pressure. Heavy grazing leads to the excessive defoliation of herbaceous vegetation, reducing standing biomass, basal cover and plant species diversity (Bilotta et al., 2007). The difference in OC was related to differences in the soil structure, the litter layer, the standing biomass and the basal covers by Tessema et al. (2011). These differences in OC content were less pronounced as depth increased. Soil structure is also weakened in grazed sites, being reduced from moderate to weak quality in these soils (Table 1). 
The $\mathrm{pH}$ values are higher in grazing soils, most likely due to their lower organic matter content; the greater the depth, the higher the $\mathrm{pH}$ values, as the amount of plant remains decreases. These results for organic carbon and $\mathrm{pH}$ agree with those obtained by other authors (Steffens et al., 2008; Xie and Witting, 2004; Young-Zhong, 2005). The EC decreases slightly in surface grassland horizons as previously reported by Tessema et al. (2011).

There is a decrease in larger aggregates and an increase in smaller aggregates in grazing soils compared with ungrazed soils, which may indicate the effects of compaction on grazing soils (Figure 1). The compaction process of the soil after grazing has been previously described by other authors, such as du Toit et al. (2009), Bilotta et al. (2007) and Betteridge et al. (1999). The effect of soil compaction is to decrease soil porosity, particularly the volume of the large inter-aggregate pores (macropores). Recovery of damaged soil surfaces due to improved soil porosity has also been reported after the removal of sheep in semi-arid woodlands. The porosity of areas left ungrazed for either 8 or 16 years was greater than that of regularly grazed soils (Drewy, 2006).

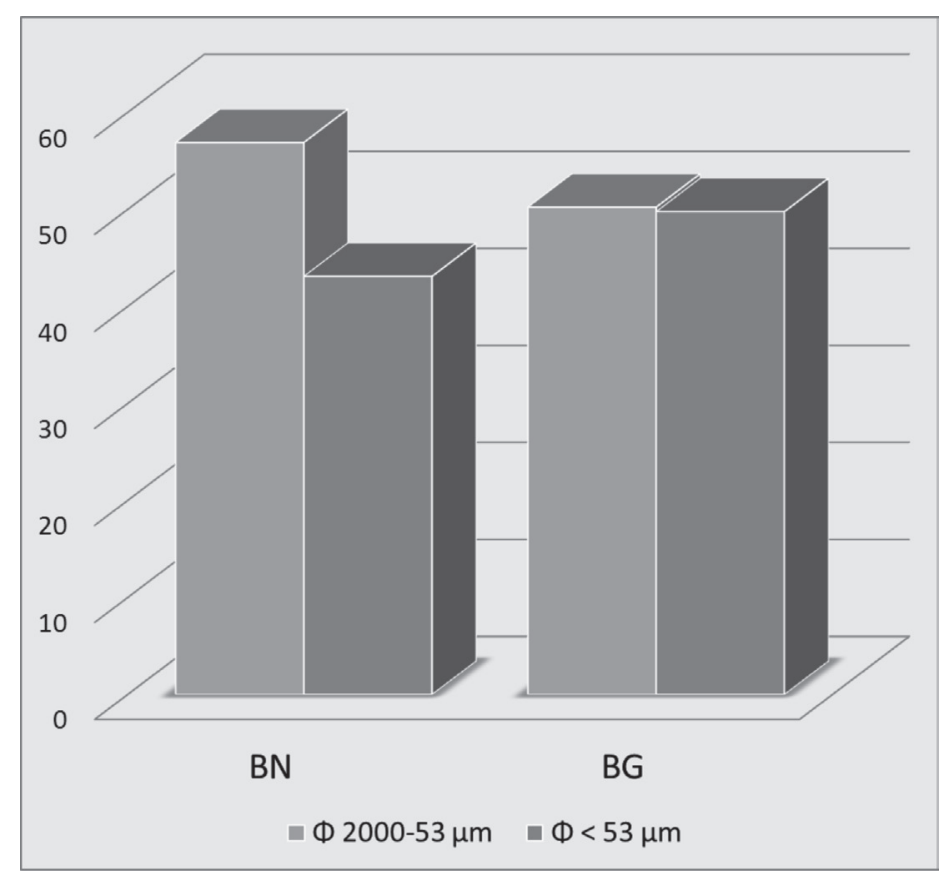

Figure 1. Average percentage (\%) in weight of aggregates, obtained in a moist state for natural soils (BN) and for grazing soils (BG).

Table 2 shows the average values for the physical properties of the soils for the two experimental treatments. A decrease in the porosity of grazing soils can be observed in comparison with natural soils; this re- sult can be explained by compaction through the action of sheep. The moderately high amount of clay in the soils in the area (>25\%) (González and Candás, 2004), the lower proportion of organic carbon and the 
greater percentage of fine aggregates points to the alteration of macropores into micropores, as there is also an increase in micropore number in impacted soils. A decrease in macropores leads to a reduction in soil aeration and a tendency towards surface flooding (Proffitt et al, 1995); macroporosity is thus an important indicator of soil quality (Drewry et al., 2008). A slight increase was observed in the bulk density values for soils under grazing (du Toit et al., 2009; Greenwood et al., 1998; Warren et al., 1986), and the values for particle density, which is conditioned by the mineral nature of the soils, were similar. Water retention is slightly lower in grazing soils than in natural soils due to their lower organic matter content (Golodets and Boeken, 2006). The moisture percentage, however, is somewhat greater in impacted soils; this could be caused by a reduction in the moisture loss through transpiration in these areas (Stavi et al., 2008).

Table 2. Average values $(n=3)$ of physical properties of natural recovery soils after animal exclusion (BN) and grazing soils $(\mathrm{BG})$, determined from unaltered samples.

\begin{tabular}{lcc}
\hline & BN & BG \\
\hline Porosity (\%) & 43.76 & 38.41 \\
Bulk density (g/cm3) & 1.39 & 1.50 \\
Particle density (g/cm3) & 2.48 & 2.44 \\
Water retention (\%) & 20.80 & 18.52 \\
Moisture (\%) & 31.12 & 33.22 \\
\hline
\end{tabular}

There is a significant negative correlation between OC and apparent soil density $(\mathrm{r}=-0.891 * * ; * *$ correlation significance level 0.01), which highlights the influence of organic components on soil density. This correlation has been previously described by other authors (Stavi et al., 2008). There is also a negative correlation, although not a significant one, between $\mathrm{pH}$ and $\mathrm{OC}$; greater OC contents are associated with lower $\mathrm{pH}$ values. There is a very significant negative correlation between bulk density and water retention $\left(\mathrm{r}=-0.968^{* *}\right)$ and a significant positive correlation between bulk density and moisture $\left(\mathrm{r}=0.856^{*}\right.$; *correlation significance level 0.05 ). Moisture is negatively and significantly correlated with porosity $\left(\mathrm{r}=-0.869^{*}\right)$, and pore size plays a more important role than total porosity; the larger the pore, the higher the moisture content, as water will be less easily lost from the soil. There is also a significant negative correlation $\left(r=-0.845^{*}\right)$ between moisture and water retention. Finally, it is worth noting the nonsignificant positive correlation of porosity and OC due to the influence of organic components in the formation of aggregates (Bronick and Lal, 2005).

The analysis of variance of the average values (ANOVA) highlights the significant differences between natural soils and soils impacted by the action of sheep regarding organic carbon $(0.014)$, bulk density (0.003) and water retention (0.018).

The anthropic action of grazing produces modifications in the characteristics and physical properties of soils, fundamentally on the surface levels (0-10 $\mathrm{cm})$, as has been demonstrated by analytical methods. A decrease in the content of organic carbon, a slight increase in bulk density and a decrease in the percentage of water retention were observed in grazing soils in comparison with no grazing systems. There is also an increase in smaller-sized aggregates $(<53 \mu \mathrm{m})$, a decrease in the percentage of porosity and an increase in moisture after grazing.

Figure 2 shows the proton density weighted images $(\mathrm{TR}=2000 \mathrm{~ms}$; $\mathrm{TE}=4.5 \mathrm{~ms})$ for 9 axial slices of sample cylinders taken from both natural recovery soil (BN) (figure 2, top) and grazing soil (BG) (figure 2, bottom). Proton density contrast is a quantitative summary of the number of protons from free water present in the sample. The higher the number of protons is in a given region of soil, the greater the transverse component of magnetisation and the brighter the resulting signal on the proton density 
contrast image. Conversely, the lower the number of protons is in the sample, the less the transverse magnetisation, and the darker the signal on the proton density weighted images. The visual analysis of the signal intensity in the $\mathrm{BN}$ images shows that it is higher than the signal obtained in the BG slices as it is the MR signal related to water content (Duval et al., 2010). A different distribution of water within each sample can be observed, indicating different porosities.

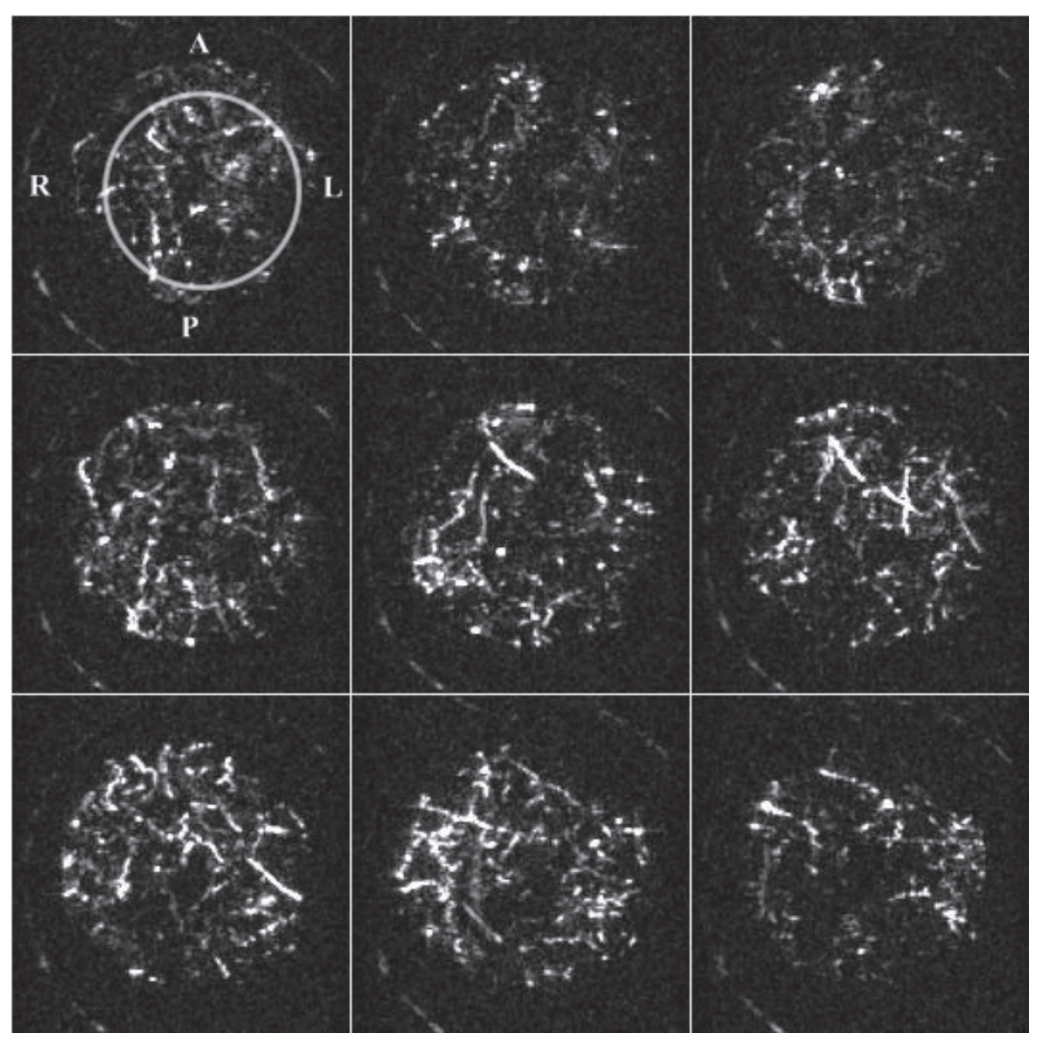

Figure 2. Proton density weighted images. Axial slices (slice thickness $=5 \mathrm{~mm}$ ) of $\mathrm{BN}$ (a) and $\mathrm{BG}(\mathrm{b})$ samples. MRI parameters: spin-echo sequence, $\mathrm{TR}=2000 \mathrm{~ms}, \mathrm{TE}=4.5 \mathrm{~ms}, \mathrm{FOV}=7 \mathrm{x} 7 \mathrm{~cm}^{2}$, matrix size $128 \mathrm{x} 128$. Soil samples were placed in methacrylate cylinders $(5 \mathrm{~cm}$ inner diameter and $5 \mathrm{~cm}$ high). Region of interest (ROI) marked on upper left corner image of figures $2 a$ and $2 b$. The outer ring and aliasing artifacts come from the radiofrequency probehead.

The calculation of the signal intensities of the MR images from each of the samples also highlights this difference. Considering the average signal intensity obtained from 10 slices in the sample, the values are twice as great for $\mathrm{BN}$ soils (2.94E05 signal intensity a.u.) than for BG soils (1.45E05 signal intensity a.u.). Similar results were found when total signal intensities were considered (5.61E10 signal intensity a.u. in $\mathrm{BN}$ soils versus $3.01 \mathrm{E} 10$ signal intensity a.u in BG soils). 
Figure 3 shows the tri-dimensional graphics of the maps of intensities obtained from the proton density weighted images. The figure provides an indication of the location of the water and therefore of the porosity of the samples. The water content of the BG (a) sample is lower than that of the natural soil sample, BN (b), which implies a lower porosity for the BG (a) soil. The numeric calculation of the percentage of porosity, based on the signal intensity of the images, also reveals a decrease in this figure for grazing soil in comparison with natural soil in all cases (Figure 4).

a.

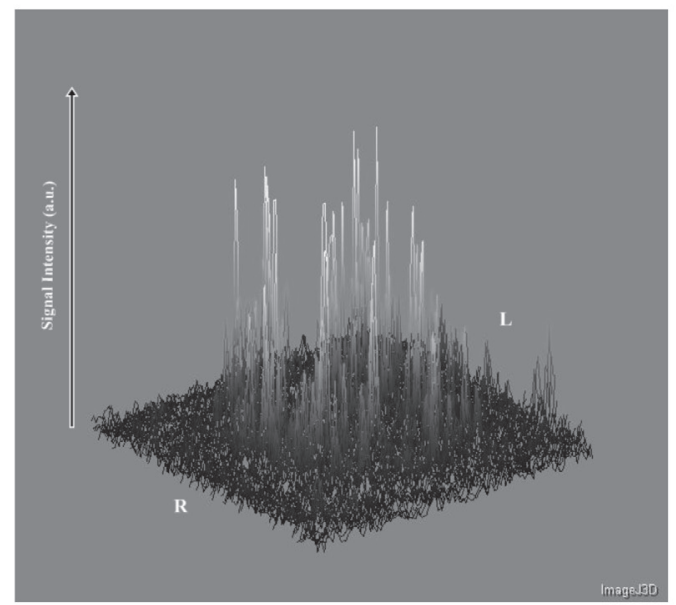

b.

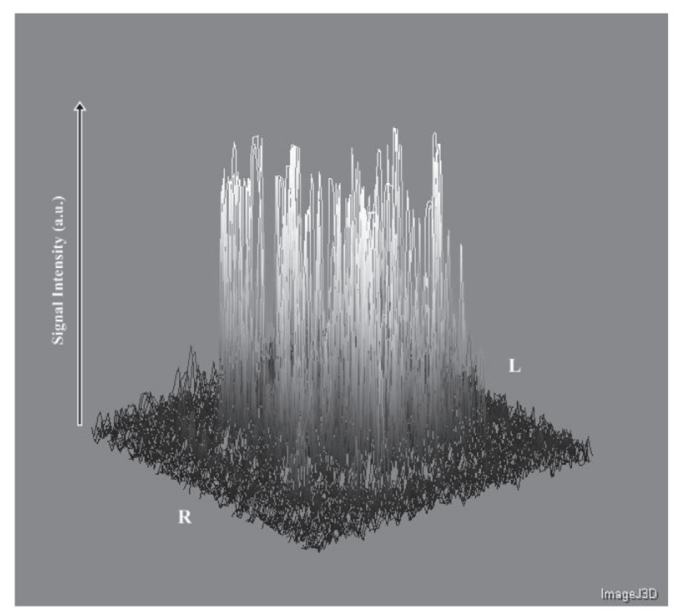

Figure 3. Tri-dimensional graphics of $2 \mathrm{D}$ intensity maps obtaining from the proton density weighted images (a. grazing soil (BG); b. natural recovery soil (BN)). 


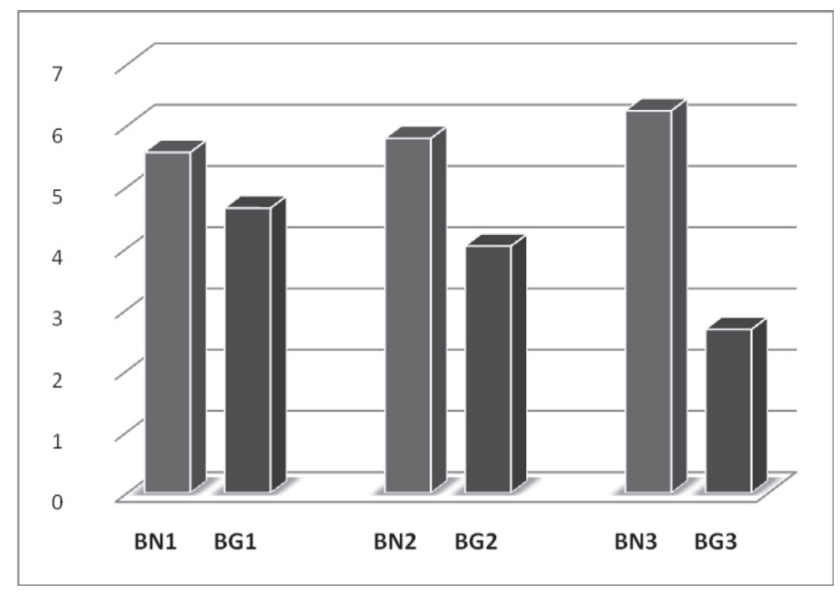

Figure 4. Porosity (\%) calculated using MR techniques. The percentage of porosity based on the signal intensity of the images reveals lowest values in grazing soil (BG samples) than in natural recovery soil (BN samples).4

The local determination of porosity using NMR imaging techniques was previously reported in heterogeneous samples, such as carbonate cores (Borgia et al., 1996), confirming the quality of the method as a tool for measuring porosity in these matrices.

The study of the parameters T1 and T2 (relaxation times inherent in each sample) supplements the porosity study conducted using MRI because it allows us to differentiate between samples, or between regions of a sample, with the same local porosity but different pore sizes (Borgia et al, 2001).

The effects of water content on NMR parameters may be described from the T2 curve (Duval et al., 2010). As the initial signal intensity is proportional to the sample proton content, and because water is the most abundant protonic structure in our system, this result explains the reduction in signal intensity observed for grazing soils in comparison with ungrazed soils. The water relaxation time is highly sensitive to water content, which explains the more rapid decrease in the $\mathrm{T} 2$ signal observed for the grazing soils.

T2 relaxation is directly related with molecular mobility, i.e., slower molecular mobility is associated with shorter relaxation time (Duval et al., 2010). The values for $\mathrm{T} 2$ relaxation time are therefore related with pore sizes, and samples with larger pore sizes have longer T2 relaxation times (Viola et al., 2006; Appolonia et al., 2001). Bird et al. (2005) associated long relaxation times with the free water located between the aggregates and in the interiors of the larger-sized pores, whereas shorter relaxation times were associated with the water bound to the smaller-sized pores located inside the aggregates.

If we observe the curve for T2 (Figure 5), we can see a sharper drop in the curve (shorter T2 relaxation time) for the grazing soil sample (average of BG1, BG2, BG3). This result indicates a greater content of bound water and a smaller pore size.

The natural recovery soil sample from the grazing exclusion condition (average of BN1, BN2, BN3) shows a slower drop in the $\mathrm{T} 2$ curve due to the longer $\mathrm{T} 2$ relaxation time. This result is associated with the presence of a greater quantity of free water in this soil and a greater pore size. 

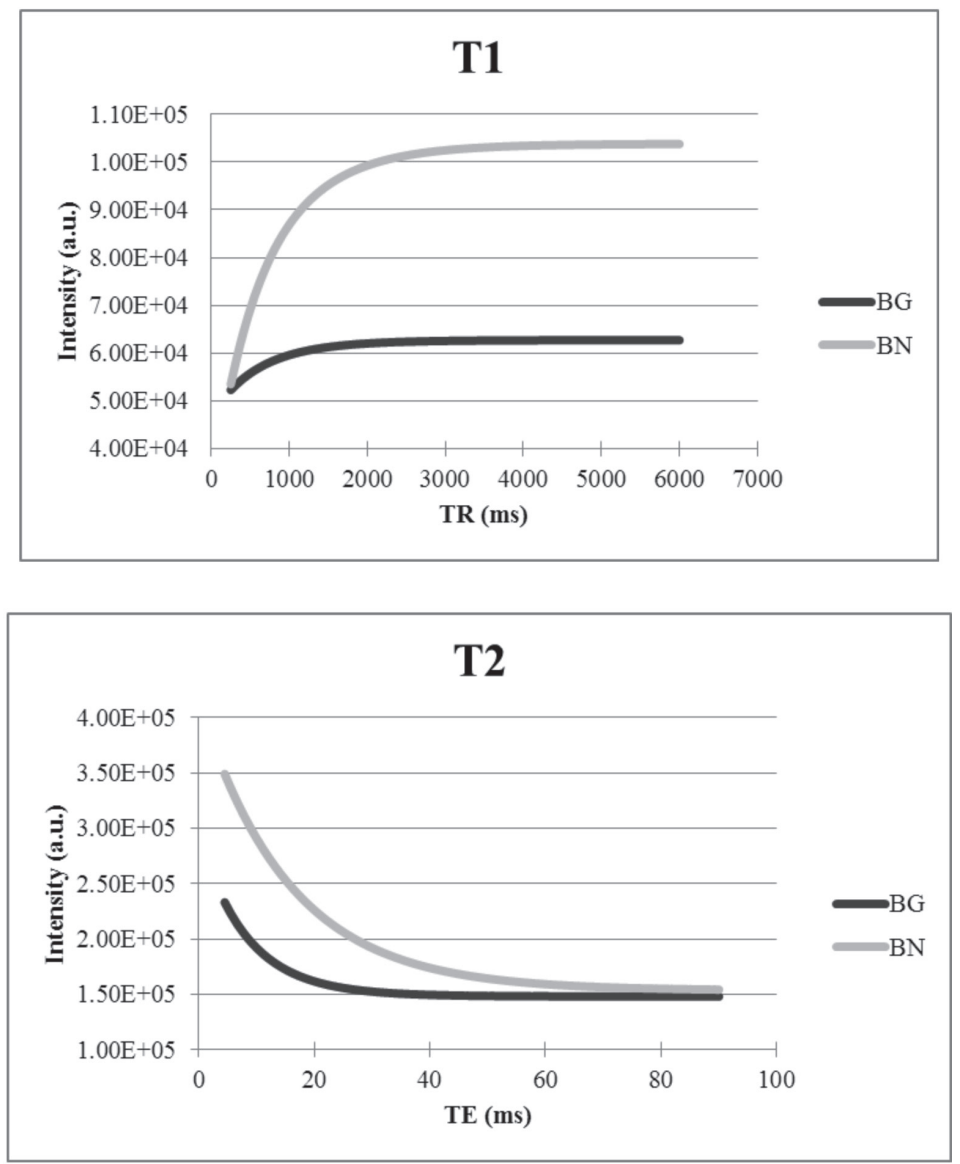

Figure 5. Relaxation time $\mathrm{T} 1$ and $\mathrm{T} 2$ curves obtained from MRI experiments. ( $\mathrm{T} 1$ parameters: $\mathrm{TE}=4.5 \mathrm{~ms}$, $\mathrm{TR}$ varied from 250 to $6000 \mathrm{~ms}$; T2 parameters: TR=2000 ms, TE varied from 4.5 to $90 \mathrm{~ms}$ ). Both T1 and T2 curves have been obtained for grazing soils (BG samples) and natural recovery soils (BN samples).

T1 Relaxation time is known to be an indicator of water mobility and its interactions with environmental conditions such as polymer presence and pore size (Faure and Rodts, 2008). In bulk water, every molecule has the same environment, and a single T1 value is observed for the sample. In complex media, such as soil, water molecules embedded in the sample may be confined in pores of different sizes. Because these molecules may experience different local environ- ments, relaxation data become multi-exponential, and various $\mathrm{T} 1$ values may be exhibited. A well-known trend is that T1 usually decreases with decreasing pore size (Faure and Rodts, 2008).

If we observe the curve for T1 (Figure 5), we can deduce a similar behaviour of the soils as that described for the $\mathrm{T} 2$ curve.

The "BG average" sample has a shorter $\mathrm{T} 1$ value than the "BN average" sample, showing that its lon- 
gitudinal magnetisation is recovered much more rapidly. This indicates the presence of a greater quantity of bound water in soils under grazing conditions and therefore a lower pore size in grazing soils $(\mathrm{BG})$ than in the recovery treatment (BN).

For other complex media, such as cement pastes, long $\mathrm{T} 1$ relaxation time values were attributed to water with free movement between cement grains, while short $\mathrm{T} 1$ values were attributed to water inside the cement grains that had less mobility (Faure and Rodts, 2008).

Similar T1 and T2 curves were reported for two sludge mixtures with different dry matter percentages (Duval et al., 2010).

The shapes of the relaxation time distribution vary in terms of peak position (peak relaxation time) and peak intensity (peak water content), as has previously been reported for different soils (Jaeger et al., 2009). There is a correspondence between the distribution of the pore size in the sample and the distribution of the $\mathrm{T} 1$ and T2 relaxation times (Kleinberg, 1994). Narrow $\mathrm{T} 1$ distributions are an indication of micro-structural homogeneity and thus of the presence of pores of similar sizes. In contrast, broad T1 distributions show the presence of a wide distribution of pore sizes (Viola et al., 2006; Bird et al., 2005).

The relaxation time $\mathrm{T} 1$ distributions for $\mathrm{BN}$ and BG soils are shown in figure 6. The grazing soil (BG) has a narrow distribution, indicating a greater homogeneity and the presence of pores of nearly the same dimensions. On the contrary, the BN sample has a wider distribution of $\mathrm{T} 1$, which suggests a wider pore size distribution for the natural soil sample.

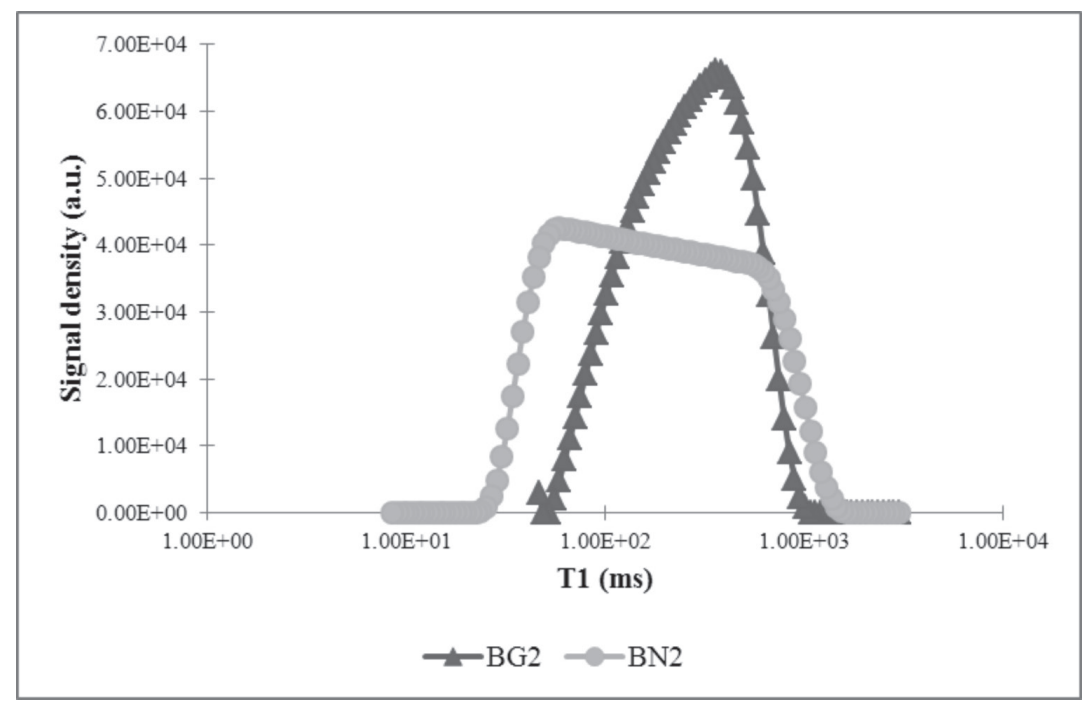

Figure 6. Relaxation time T1 distribution curves of the soil specimens under grazing (BG) and natural recovery (BN), obtained by Nuclear Magnetic Resonance (Relaxometry) using a standard IR sequence. 
The values for $\mathrm{T} 2$ follow a bimodal distribution for the two samples, reflecting the presence of two different pore sizes in both $\mathrm{BG}$ and $\mathrm{BN}$ soils (Figure 7). The initial maximum, with lower T2 values, corresponds to pores with smaller sizes, which are found in higher concentrations in the sample that has undergone compaction. The pores with larger sizes are related with higher T2 values (to the right of the distribution). These values are more abundant in the natural recovery soil sample. It is worth noting that although there is a bimodal distribution of $\mathrm{T} 2$ for the no grazing areas, it shows less clearly defined peaks, indicating that the sample is less homogeneous than that of the grazing soils.

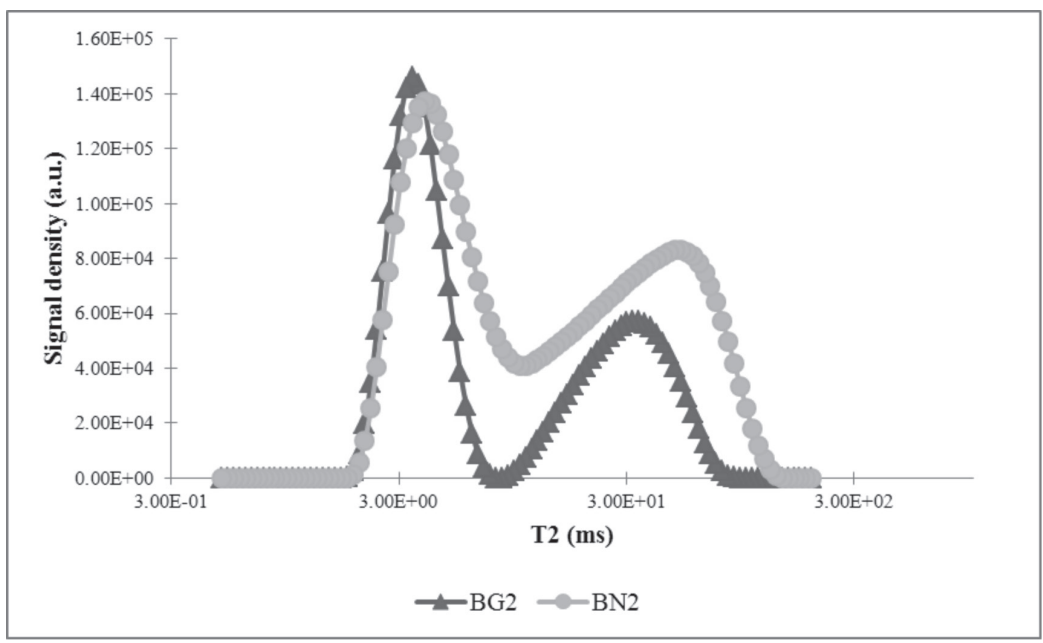

Figure 7. Relaxation time T2 distribution curves of the soil specimens under grazing (BG) and natural recovery (BN), obtained by Nuclear Magnetic Resonance (Relaxometry) using a CPMG sequence.

Correlation analyses were conducted between the porosity determined by MR and the values of the relaxation times ( $\mathrm{T} 1$ and $\mathrm{T} 2$ ) and the soil parameters and physical properties of the soils determined in the laboratory.

A very significant positive correlation $(\mathrm{r}=$ $0.932 * *)$ was found between the porosities determined in the analyses and those obtained in the MR images, which confirms the validity of this technique for determining the porosity of a porous medium, such as soil, using the parameters for the acquisition of images described in the Methods section.
Moreover, a significant positive correlation was found for the porosity values obtained by MR and water retention $\left(\mathrm{r}=0.861^{*}\right)$, whereas significant negative correlations were observed between porosity and bulk density $\left(r=-0.848^{*}\right)$ and porosity and moisture $(r=$ $-0.827 *)$. A positive and significant correlation was also obtained between relaxation times and analytical porosity $\left(\mathrm{r}=0.985^{*}\right)$.

These results demonstrate the complementary nature of both MRI and MRR techniques in the study of the porosity and their usefulness for the assessment of soil compaction in a soil structure recovery study. 


\section{Conclusions}

The application of the Magnetic Resonance Imaging and ${ }^{1} \mathrm{H}$ NMR relaxometry analytical methods has shown that grazing soils become more densely packed in comparison with no grazing soils. This impact produces a decrease in porosity and consequently reduced water retention. We examined the potential for grazing exclusion to promote the natural regeneration of these soil physical properties. The natural recovery of deteriorated soil physical condition after grazing is limited to $10 \mathrm{~cm}$ of depth.

Transverse relaxation NMR measurements have been used to study the pore space characteristics of both treatments (grazing and ungrazing soils). There is a greater proportion of smaller-sized pores and a greater homogeneity between them in grazing soils in comparison with soils recovered after ten years of animal exclusion.

The correlation between analytical porosity and porosity calculated by imaging, as well as relaxation times, further validates the MR technique for the study of a porous system such as soil.

The results confirm the quality of the applied methods and the use of MR imaging and relaxometry as valid tools for measuring the effects of grazing systems on soil compaction, as well as for analysing the porosity and estimating the water content of soils.

\section{Acknowledgements}

The authors are grateful to $M^{a}$.E. Fernández Valle, from MR C.A.I. (UCM), for her support with MRI data acquisition and Relaxometry analyses.

\section{References}

Appolonia, L., Borgia C.G., Bortolotti,V., Brown R.J.S., Fantazzini, P., Rezzaro,G. 2001. Effects of hydrophobic treatments of stone on pore wa- ter studied by continuous distribution analysis of NMR relaxation times. Magnetic Resonance Imaging 19, 509-512.

Betteridge, K., MacKay,A.D., Barker, D.J., Shepherd,T.G., Budding, P.J., Devantier,B.P., Costall, D.A. 1999. Effect of cattle and sheep treading on surface configuration of a sedimentary hill soil. Australian Journal of Soil Research 37, 743-760.

Bilotta, G.S., Brazier R.E., Haygarth P.M. 2007. The impacts of grazing animals on the quality of soils, vegetation, and surface waters in intensively managed grasslands. Advances in Agronomy 94, $237-$ 280.

Bird, N.R.A., Preston A.R., Randall E.W., Whalley, W.R., Whitmore A.P. 2005. Measurement of the size distribution of water-filled pores at different matric potentials by stray field nuclear magnetic resonance. European Journal of Soil Science 56, 135-143.

Bisigato, A. J., Laphitz, R. M. L., and Carrera, A. L. 2008. Non-linear relationships between grazing pressure and conservation of soil resources in $\mathrm{Pa}-$ tagonian Monte shrublands. Journal of Arid Environments $72,1464-1475$.

Borgia, G.C., Bortolotti V., Dattilo, P., Fantazzini P. Maddinelli, G. 1996. Quantitative determination of porosity: a local assessment by NMR Imaging techniques. Magnetic Resonance Imaging 14, 7/8, 919-921.

Borgia, G.C., Bortolotti V., Fantazzini P. 2001. Changes of the local pore structure quantified in heterogeneous porous media by ${ }^{1} \mathrm{H}$ magnetic resonance relaxation tomography. Journal of Applied Physics 90, 3, 1155-1163.

Bortolotti, V., Caimati,M., Casieri C., De Luca F., Fantazzini, P., Terenzi,C. 2006. Water absortion kinetics in different wettability conditions studied at pore and sample scales in porous media by 
NMR with portable single-sided and laboratory imaging devices. Journal of Magnetic Resonance 181, 287-295.

Bortolotti, V., Gombia,M., Cernich,F., Michelozzi,E., and Fantazzini,P. 2006b. A study to apply nuclear magnetic resonance porosity measurements to seabed sediments. Marine Geology 230, 21-27.

Bronick, C.J. and Lal, R. 2005. Soil structure and management: a review. Geoderma 124, 3-22.

Brownstein, K.R. and and Tarr C.E. 1979. Importance of classical diffusion in NMR studies of water in biological cells. Physical Review A. 19, 24462453.

Cambardella, C.A. and Elliot E.T., 1992. Particulate organic matter changes accross a grassland cultivation sequence. Soil Science Society of American Journal 56, 777-783.

Casermeiro, M. A., Molina, J. A., Cruz Caravaca, M. T., Hernando Costa, J., Hernando Massanet, M. I., and Moreno, P. S. 2004. Influence of scrubs on runoff and sediment loss in soils of Mediterranean climate. Catena 57, 91-107.

Daum, D.R. 1996. Soil Compaction and Conservation Tillage. Penn State College of Agricultural Sciences. The Pennsylvania State University 5M96.

Drewry, J.J. 2006. Natural recovery of soil physical properties from treading damage of pastoral soils in New Zealand and Australia: A review. Agriculture, Ecosystems and Environment 114, 159-169.

Drewry, J. J., Cameron, K. C., and Buchan, G. D. 2008. Pasture yield and soil physical property responses to soil compaction from treading and grazing-a review. Australia Journal of Soil Research 46, 237-256.

Du Toit, G. V., Snyman, H. A., and Malan, P. J. 2009. Physical impact of grazing by sheep on soil parameters in the Nama Karoo subshrub/grass rangeland of South Africa. Journal of Arid Environments $73,804-810$.
Duval, F.P., Quellec,S., Trqmier,A., Druilhe,C., and Mariette,F. 2010. Non-destructive quantification of water gradient in sludge composting with Magnetic Resonance Imaging. Waste Management 30, 610-619.

FAO, 2007. IUSS Grupo de Trabajo WRB. Base Referencial Mundial del Recurso Suelo. Primera actualización 2007. Informes sobre Recursos Mundiales de Suelos No. 103. FAO, Roma.

Faure, P.F. and Rodts,S. 2008. Proton NMR relaxation as a probe for setting cement pastes. Magnetic Resonance Imaging 26, 1183-1196.

Glinski, J. and Lipiec, J., 1990. Soil physical conditions and plant roots. C.R.C. Press Inc. Florida.

Golodets, C. and Boeken, B. 2006. Moderate sheep grazing in semiarid shrubland alters small-scale soil surface structure and patch properties. Catena 65, 285-291.

González, J. and Candás, Mª A. 2004. Materia orgánica en suelos de bosques sabineros Juniperus thurifera $L$. Edafología 112, 119-135.

Greenwood, K. L., MacLeod, D. A., Scott, J. M., Hutchinson, and K.J. 1998. Changes to soil physical properties after grazing exclusion. Soil and Use Management 14, 19-24.

Hall L.D., Amin M.H.G., Dougherty E., Sanda M., Votrubova J., Richards K.S., Chorley R.J., Cislerova M., 1997. MR properties of water in saturated soils and resulting loss of MRI signal in water content detection at $2 \mathrm{~T}$. Geoderma 80 , 431-448.

ISRIC. 2002. Procedures for soil analysis. International Soil Reference and Information Centre, FAO.

Jaeger, F., Bowe,S., Van As,H., and Schaumann,G.E. 2009. Evaluation of $1 \mathrm{H}$ NMR relaxometry for the assessment of pore-size distribution in soil samples. European Journal of Soil Science 60, 10521064. 
Kleinberg, R.L. 1994. Pore size distributions, pore coupling and transverse relaxation spectra of porous rocks. Magnetic Resonance Imaging 12, 2, 271-274.

Koorevaar, P., Menelik G., Dirksen C. 1983. Elements of soil physics. Elsevier. Amsterdam.

Li, C., Hao X., Zhao M., Han G., Willms W.D. 2008. Influence of historic sheep grazing on vegetation and soil properties of a Desert Steppe in Inner Mongolia. Agriculture, Ecosystems and Environment 128, 109-116.

Linnartz, N.E., Chung-Yun, H., Dunval, V.L. 1966. Grazing impairs physical properties of a forest soil in central Lousiana. Journal of Forestry 64, 239-243.

López-Arce, P., Gómez-Villalba, L. S., Pinho, L., Fernández-Valle, M. E., de Buergo, M., and Fort, R. 2010. Influence of porosity and relative humidity on consolidation of dolostone with calcium hydroxide nanoparticles: Effectiveness assessment with non-destructive techniques. Materials Characterization 61, 168-184.

Martinez, L.J. and Zinck J.A. 2004. Temporal variation of soil compaction and deterioration of soil quality in pasture areas of Colombian Amazonia. Soil and Tillage Research 75, 3-17.

Munsell. 2009. Soil color charts. Ed. Company Baltimore, USA.

Prebble, R.E. and Currie,J.A. 1970. Soil Water Measurement by A Low-Resolution Nuclear Magnetic Resonance Technique. Journal of Soil Science 21, 273-288.

Proffitt, A. P. B., Bendotti, S., and McGarry, D. 1995. A comparison between continuous and controlled grazing on a red duplex soil. I. Effects on soil physical characteristics. Soil and Tillage Research $35,199-210$.

Schauman, G.E., Hobley E., Hurra J., Rotardm W. 2005. H-relaxometry to monitor wetting and swelling kinetics in high-organic soils. Plant and Soil 275, 1-20.

Schulten, H. R. and Leinweber, P. 2000. New insights into organic-mineral particles: composition, properties and models of molecular structure. Biology and Fertility of Soils 30, 399-432.

Sigua, G.C., Coleman,S.W., and Albano,J. 2009. Beef cattle pasture to wetland reconversion: Impact on soil organic carbon and phosphorus dynamics. Ecological Engineering 35, 1231-1236

Stavi, I., Ungar, E. D., Lavee, H., and Sarah, P. 2008. Grazing-induced spatial variability of soil bulk density and content of moisture, organic carbon and calcium carbonate in a semi-arid rangeland. Catena 75, 288-296.

Steffens, M., Kölbl,A., Totsche K.U., Kögel-Knabner I. 2008. Grazing effects on soil chemical and physical properties in a semiarid steppe of Inner Mongolia PR.China. Geoderma 143, 63-72.

Tessema, Z.K., de Boer,W.F., Baars,R.M.T., and Prins,H.H.T. 2011. Changes in soil nutrients, vegetation structure and herbaceous biomass in response to grazing in a semi-arid savanna of Ethiopia. Journal of Arid Environments 75, 662-670.

USDA. United States Department of Agriculture. Soil Quality Institute. 1999. Soil Quality Test Kit Guide, ED. USDA, USA, 69-74.

Van As, H. and Van Dusschoten D. 1997. NMR methods for imaging of transport processes in microporous systems. Geoderma 80, 389-403.

Viola, R., Tucci A., Timellini G., Fantazzini P. 2006. NMR techniques: a non destructive analysis to follow microstructural changes induced in ceramics. Journal of European Ceramic Society 26, 3343-3349.

Warren, S. D., Nevill, M. B., Blackburn, W. H., and Garza, N. E. 1986. Soil response to trampling under intensive rotation grazing. Journal of Soil Science 50, 1336-1341. 
Xie, Y. and Witting, R. 2004. The impact of grazing intensity on soil charactereristics of Stipa grandis and Stipa bungeana steppe in northern China. Acta Oecologica 25, 197-204.

Young, I. R., Bailes, D. R., Burl, M., Collins, A. G., Smith, D. T., McDonnell, M. J., Orr, J. S., Banks,
L. M., Bydder, G. M., Greenspan, R. H. and Steiner, R. E. 1982. Initial Clinical Evaluation of a Whole Body Nuclear Magnetic Resonance (NMR) Tomograph. Journal of Computer Assisted Tomography 6 (1), 1-18. 